\title{
Fluid Similarity Criterions in Aircraft Landing Gear
}

\author{
Liu Xiang-yong ${ }^{1}$, Li Wan-li ${ }^{1}$, Xu Zhi-qiang ${ }^{2}$ \\ ${ }^{1}$ School of Mechnical Engineering, Tongji University, NO:4800 Caoan Highway, Shanghai, China. \\ ${ }^{2}$ The Institute of Fishery Machinery and Equipment, NO:63 Chifeng Road, Shanghai, China.
}

\begin{abstract}
Facing the design difficulty and risk of aircraft landing gear, the fluid similarity theory and model experiments are used to predict large prototype's property, which provide guidance for hydraulic designation and selection to reduce risk. Firstly, the matrix method is used to establish the fluid similarity relationship between the prototype and the model's luffing mechanism, and the above conclusions are used to design the prototype's hydraulic system. Secondly, the luffing mechanism's dynamical model with accumulator was established, the initial motion condition was set, and the pressure's similarity ratio is obtained by simulation method. Finally, the dynamic model and similarity ratio about time, velocity and pressure are verified by the prototype and model's experimental data.
\end{abstract}

\section{Introduction}

Aircraft landing gear is an important aircraft load bearing mechanism, and the aircraft landing gear include luffing cylinder and hoisting leg, as shown in Fig.1. [1] In history, there have been many design failures on the aircraft landing gear, and the mechanism can't bear load. In order to reduce the design difficulty and risk, it is urgent and necessary to use the shrunken model to predict the large prototype's performance. Besides, the similarity research has important theoretical and engineering value.

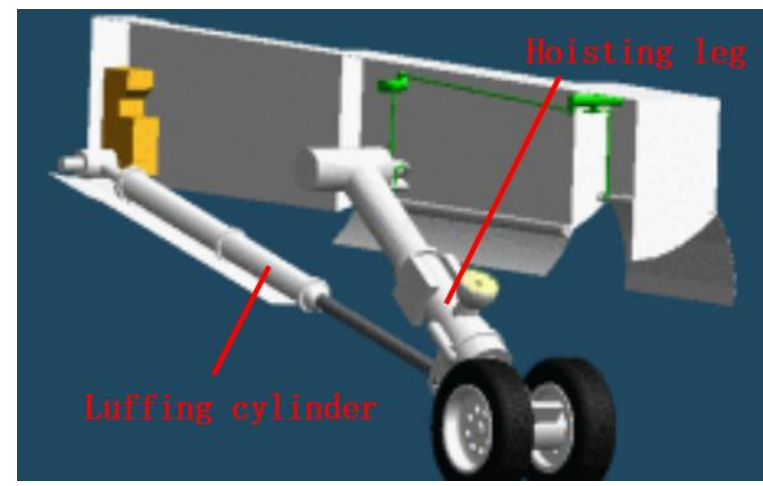

Figure.1 Aircraft landing gear

At present, scholars have done similarity research in some areas. Yang Jun-jie deduced the similarity theory and do the model experiment. Chen Xing-hua did the large structure test and comparision. Gezary did the micro dynamic similar model flight test. $\mathrm{Li}$ Gao did the similarity research of arch dam vibration. Cheng Su-qiu did the scaling laws application in underwater explosion models [2-9].
All of the above researches are based on the well-known equations, but the fluid's similarity research and its application in aircraft landing gear are rare. Our contribution is to establish the fluid similarity theory by computational fluid dynamics method and fluid similarity theory; The theory was verified by simulation and experiments.

\section{Similarity criterions based on matrix method}

The electro-hydraulic proportional directional valve controls the luffing cylinder's outstretch and retraction movement; In order to reduce the pump demand, an accumulator was added in the cylinder's large cavity, and the accumulator plays an energy-saving role [10-13].

\subsection{Deduce the similarity criterions}

The incompressible fluid was the research target, and the relationship among the pressure $(\mathrm{P})$, oil viscosity $(\mu)$, acceleration $(\mathrm{g})$, velocity $(\mathrm{w})$, length $(l)$, and density $(\rho)$ were built.

$$
\Pi=p^{a} \mu^{b} g^{c} w^{d} l^{e} \rho^{f}
$$

The mass (M), length (L), time (T) were the basic factors, and the total relationship is:

$$
\Pi=\left[M L^{-1} T^{-2}\right]^{a}\left[M L^{-1} T^{-1}\right]^{b}\left[L T^{-2}\right]^{c}\left[L T^{-1}\right]^{d}[L]^{e}\left[M L^{-3}\right]^{f}(1)
$$

Get the following power matrix form: 


\begin{tabular}{lcccccc}
\multicolumn{1}{c}{} & $\mathrm{a}$ & $\mathrm{b}$ & $\mathrm{c}$ & $\mathrm{d}$ & $\mathrm{e}$ & $\mathrm{f}$ \\
\multicolumn{1}{c}{} & $\mathrm{p}$ & $\mu$ & $\mathrm{g}$ & $\mathrm{w}$ & $\mathrm{l}$ & $\rho$ \\
\cline { 2 - 7 } $\mathrm{M}$ & 1 & 1 & 0 & 0 & 0 & 1 \\
$\mathrm{~L}$ & -1 & -1 & 1 & 1 & 1 & -3 \\
$\mathrm{~T}$ & -2 & -1 & -2 & -1 & 0 & 0 \\
\multicolumn{2}{l}{ Since } & the $\mathrm{M}, \mathrm{L}$ and & $\mathrm{T}$ have & no & relationship, the
\end{tabular}

Since the $\mathrm{M}, \mathrm{L}$ and $\mathrm{T}$ have no relationship, the following three equations are obtained from the power matrix:

$$
\left.\begin{array}{c}
a+b+f=0 \\
-a-b+c+d+e-3 f=0 \\
-2 a-b-2 c-d=0
\end{array}\right\}
$$

So the following three power groups were got:

$$
\left.\begin{array}{c}
\Pi_{1}=\mathrm{pw}^{-2} \rho^{-1}=\frac{p}{\rho w^{2}} \\
\Pi_{1}=\mu w^{-1} l^{-1} \rho^{-1}=\frac{\mu}{\rho w l} \\
\Pi_{3}=\mathrm{gw}^{-2} l=\frac{g l}{w^{2}}
\end{array}\right\}
$$

\subsection{Deduce the similarity ratio and design selection}

According to the formulas (5), (6), (7), when the length $(l)$ ratio is $1: 4$ and the acceleration $(g)$ is equal, it is easy to get: the speed $(w)$ ratio is $1: 2$, the pressure $(p)$ ratio is 1 : 4 , the oil viscosity $(\mu)$ ratio is $1: 8$. According to the formula: $t=l / v$, when the model and the prototype have the same angle change, the time ratio is $1: 2$.

\section{Similarity criterions based dynamical model}

\subsection{Establish the dynamic model}

The hydraulic system's flow distribution is shown in Fig.2. Q2 is the hydraulic valve's flow, Q1 is the accumulator's flow, and Q3 is the cylinder's flow. Besides the flow in the hydraulic system also includes the compressed and leaked oil parts.

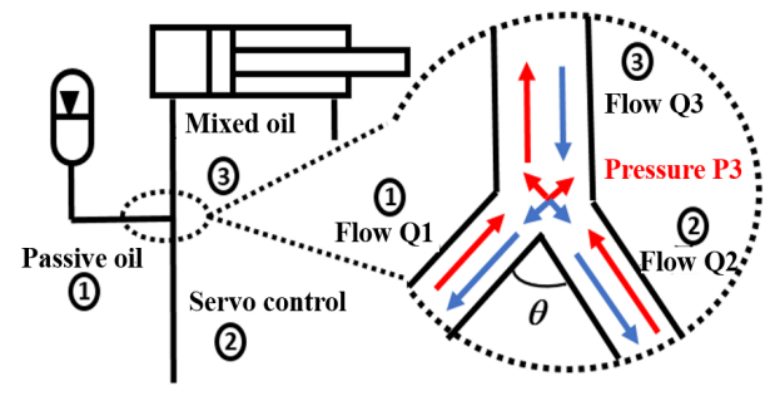

Figure.2 Mixture of accumulator oil

\subsubsection{The accumulator's dynamical model}

The capsule accumulator's structure and dynamical model are shown in Fig.3:

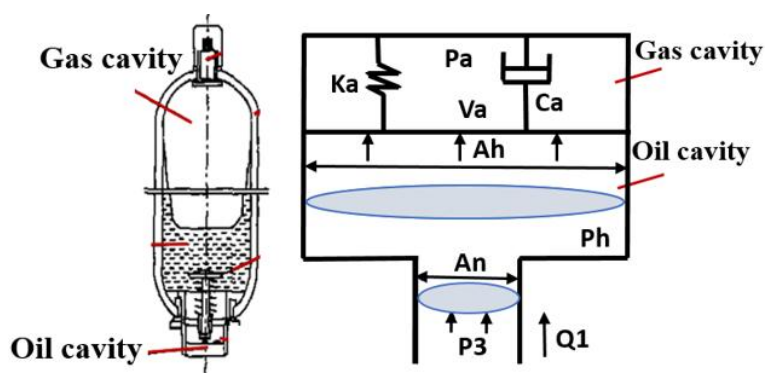

Figure.3 Accumulator and its model

In Fig.3, the accumulator's gas cavity equation can be described as followed:

$$
\left(\mathrm{p}_{\mathrm{h}}-\mathrm{p}_{\mathrm{a}}\right) \mathrm{A}_{\mathrm{a}}=\mathrm{k}_{\mathrm{e}} \frac{\mathrm{V}_{\mathrm{a}}}{\mathrm{A}_{\mathrm{a}}}+\mathrm{C}_{\mathrm{e}} \frac{1}{\mathrm{~A}_{\mathrm{a}}} \frac{\mathrm{dV}_{\mathrm{a}}}{\mathrm{dt}}
$$

In the formula (4), $\mathrm{Ke}$ is the gas stiffness coefficient, and $\mathrm{Ce}$ is the gas damping coefficient. The accumulator's oil cavity equation can be described as followed:

$$
\mathrm{p}_{3} \mathrm{~A}_{\mathrm{n}}-\mathrm{p}_{\mathrm{h}} \mathrm{A}_{\mathrm{a}}=\mathrm{m}_{\mathrm{e}} \frac{\mathrm{d}^{2} \mathrm{~V}_{\mathrm{a}}}{\mathrm{dt}^{2}} \frac{1}{\mathrm{~A}_{\mathrm{a}}}+\mathrm{B}_{\mathrm{e}} \frac{\mathrm{dV} \mathrm{a}}{\mathrm{dt}} \frac{1}{\mathrm{~A}_{\mathrm{a}}}
$$

In the formula (5), Me is the oil's equivalent mass, and $\mathrm{Be}$ is the oil's damping coefficient. Set $\mathrm{An}=\mathrm{n}$.Aa, and from the above two equations, it is easy to get the accumulator's dynamical equation:

$$
\text { n. } \mathrm{p}_{3}-\mathrm{p}_{\mathrm{a}}=\frac{1}{\mathrm{~A}_{\mathrm{a}}^{2}}\left[\mathrm{~m}_{\mathrm{e}} \frac{\mathrm{d}^{2} \mathrm{~V}_{\mathrm{a}}}{\mathrm{dt}^{2}}+\left(\mathrm{B}_{\mathrm{e}}+\mathrm{C}_{\mathrm{e}}\right) \frac{\mathrm{dV}_{\mathrm{a}}}{\mathrm{dt}}+\mathrm{k}_{\mathrm{e}} \mathrm{V}_{\mathrm{a}}\right]
$$

The gas state equation is $\mathrm{p}_{\mathrm{ao}} \mathrm{V}_{\mathrm{ao}}^{\mathrm{k}}=\mathrm{p}_{\mathrm{a}} \mathrm{V}_{\mathrm{a}}^{\mathrm{k}}$, where $\mathrm{k}(1.14)$ is the gas variable index. Do the derivation on the gas state equation:

$$
\text { n. } p_{3}=\frac{1}{A_{a}^{2}}\left[m_{e} \frac{d^{2} V_{a}}{{d t^{2}}^{2}}+\left(B_{e}+C_{e}\right) \frac{d V_{a}}{d t}+\left(k_{e}-\frac{K \cdot p_{a o}}{V_{a o}}\right) V_{a}\right]
$$

In the formula (8), V0 is the accumulator's the initial volume, and the accumulator's flow Q1 satisfies the following formula:

$$
\mathrm{Q} 1=\mathrm{V} 0-\mathrm{Va}
$$

Formula (7) can be expressed in Simulink shown in Fig4.

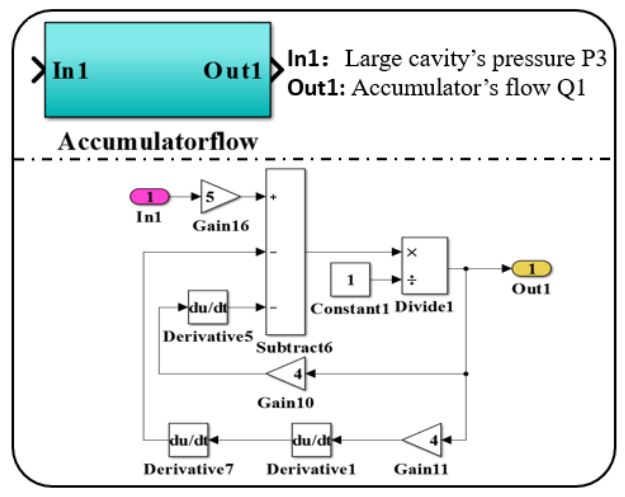

Figure.4 Accumulator's dynamic model 


\subsubsection{The Dynamical Model of Valve Control Cylinder}

In the cylinder's outstretch stage, the working state is shown in Fig.5, and the flow distribution is: $\mathrm{Q} 2=\mathrm{Q} 3-\mathrm{Q} 1$

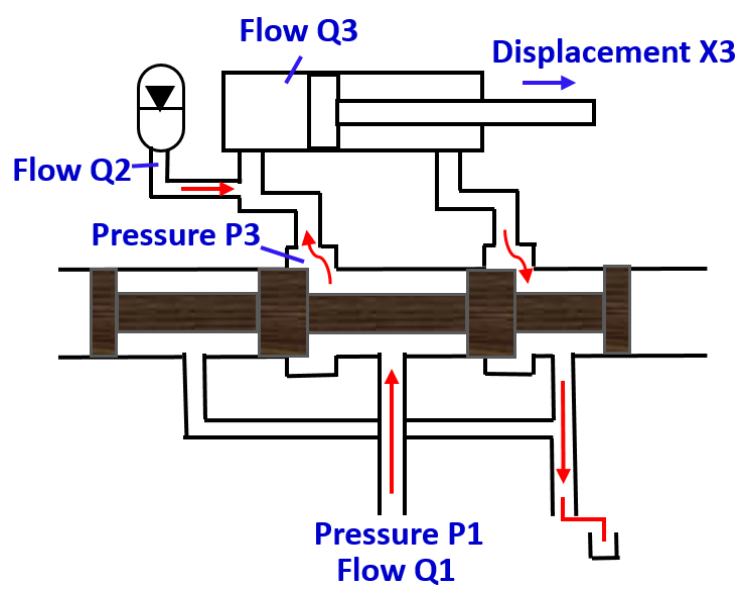

Figure.5 Cylinder's outstretch working state

The flow-continuity equation in the cylinder's outstretch stage:

$$
\begin{gathered}
\mathrm{C}_{\mathrm{d} 2} \cdot \mathrm{W}_{2} \cdot \Delta \mathrm{x}_{2} \cdot \sqrt{\frac{1}{\rho}\left(\mathrm{P}_{1}-\mathrm{P}_{3}\right)}=\left(\frac{\square}{\left.\mathrm{A}_{3} \mathrm{x}_{3}+\mathrm{C}_{\mathrm{t}} \cdot \mathrm{P}_{3}+\frac{\mathrm{V}_{\mathrm{t} 3}}{4 \beta_{\mathrm{e}}} \cdot \mathrm{p}_{3}\right)-\mathrm{Q} 1}\right. \\
\mathrm{P}_{3}=\left[\mathrm{C}_{\mathrm{d} 2} \cdot \mathrm{W}_{2} \cdot \Delta \mathrm{x}_{2} \cdot \sqrt{\frac{1}{\rho}\left(\mathrm{P}_{1}-\mathrm{P}_{3}\right)}+\mathrm{Q} 1-\mathrm{A}_{3} \mathrm{x}_{3}-\frac{\mathrm{V}_{\mathrm{t} 3}}{4 \beta_{\mathrm{e}}} \cdot \mathrm{p}_{3}\right] / \mathrm{C}_{\mathrm{t}}
\end{gathered}
$$

The dynamical model in the cylinder's outstretch stage is shown in Fig.6

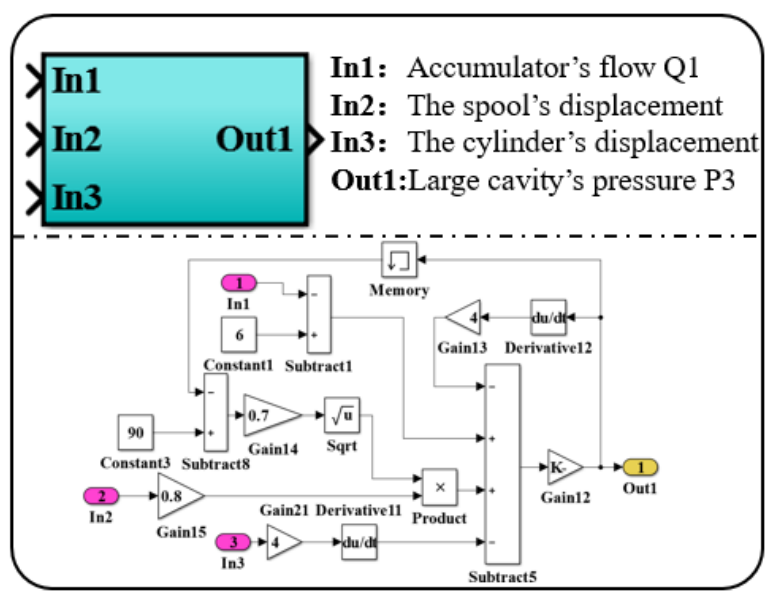

Figure.6 Cylinder's outstretch dynamic model

Combine the accumulator and the cylinder's dynamical model, and the whole simulation process is shown in Fig. 7.

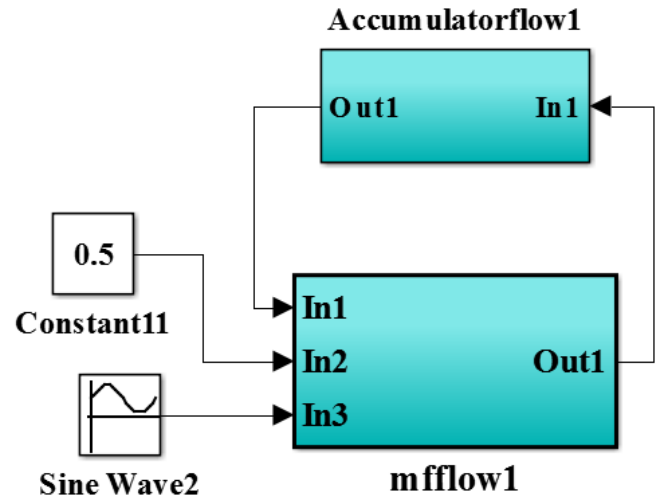

Figure.7 Hydraulic system's simulation process with accumulator

\subsection{The similarity research based on the dynamical model's simulation}

Model and prototype's cylinder outstretch movement are shown in Fig.8. Initial conditions: the length ratio is 1: 4 the used time ratio is $1: 2$, so the average speed ratio is 1 : 2 . Besides, set the valve spool's diameter ratio $1: 4$, valve spool's flow gradient ratio 1: 2 , and the accumulator's volume ratio 1: 4. Do the simulation in Fig.10.

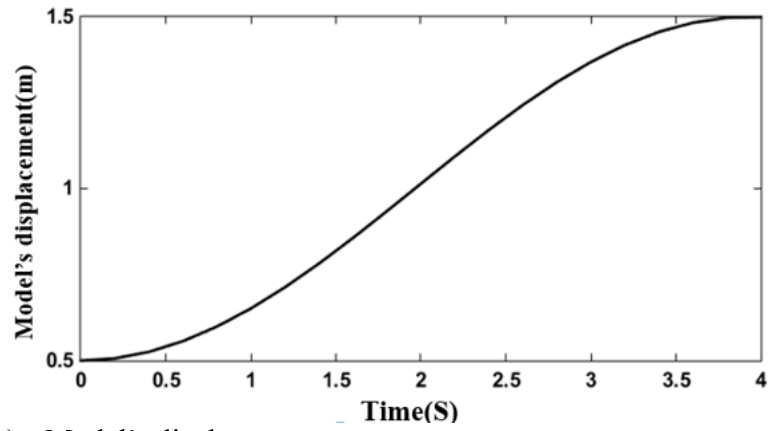

(a) Model's displacement

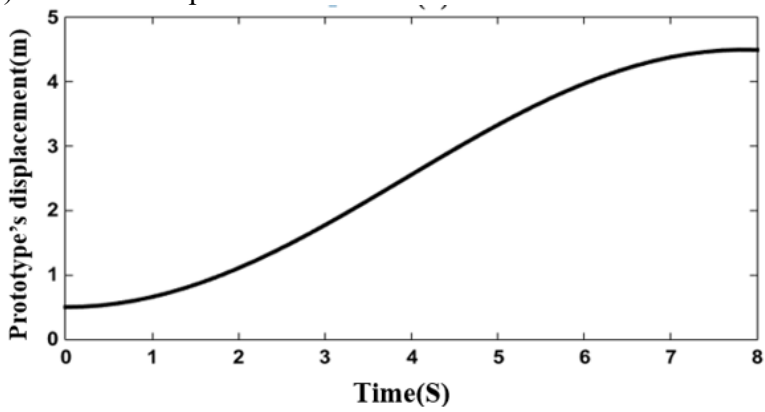

(b) Prototype's displacement

Figure.8 Cylinder's outstretch movement

The X-axis represents the valve spool's displacement, the Y-axis represents the cylinder outstretch ratio, and the Z-axis represents the cylinder's large chamber pressure. The model and prototype's outstretch simulation results are shown in Fig.9. 


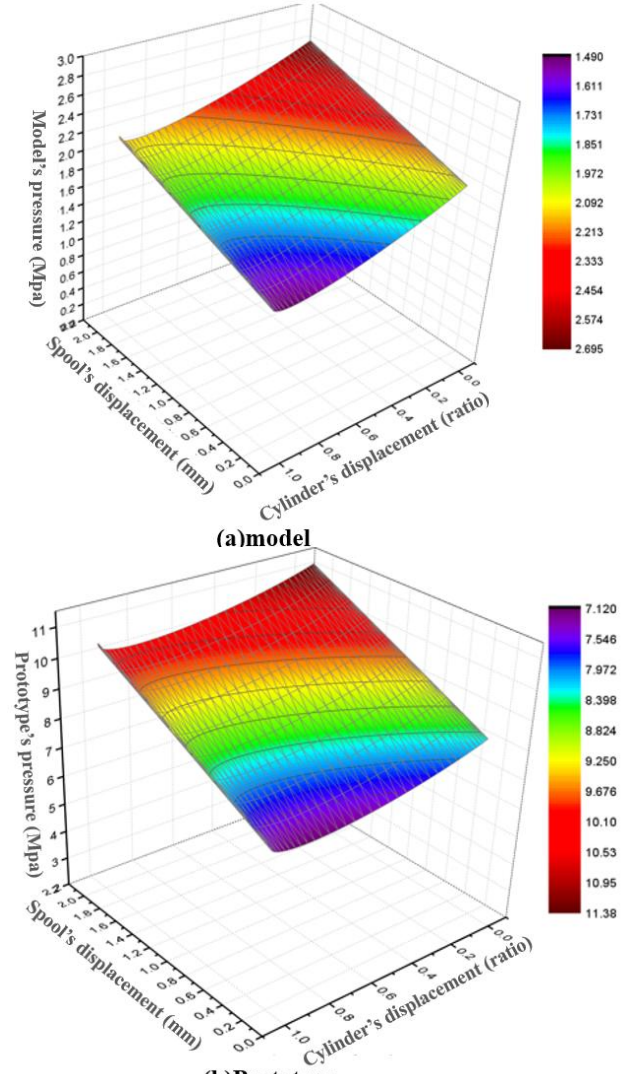

(b)Prototype

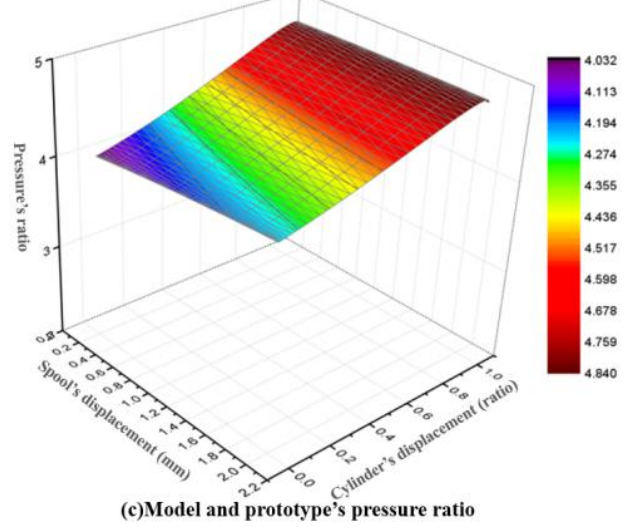

Figure.9 Cylinder's outstretch movement simulation

From the above simulation conditions, we can get that the prototype and model cylinder's length ratio is $1: 4$, the speed ratio is $1: 2$, so the calculated running-time ratio is 1: 2 . In the cylinder outsretch stage: with the decrease of the valve spool's displacement and the increase of the cylinder's extension length, the cylinder's large chamber pressure is gradually reduced, the pressure ratio is about $1: 4$, and the pressure's decrease leads to the accumulator's oil discharge process.

\section{Experimental verification}

\subsection{Luffing mechanism's Control and data acquisition}

The prototype and model are shown in Fig.10. Model's luffing mechanism: (1)The maximum displacement: 1m; (2) Maximum working speed: $1 \mathrm{~m} / \mathrm{s}$; (3) Boom angle's range: $-20^{\circ} \sim 58^{\circ}$. Prototype's luffing mechanism: (1) Maximum displacement: 4m; (2) Maximum working speed: $2 \mathrm{~m} / \mathrm{s}$; (3) Boom angle: $-20^{\circ} \sim 58^{\circ}$;

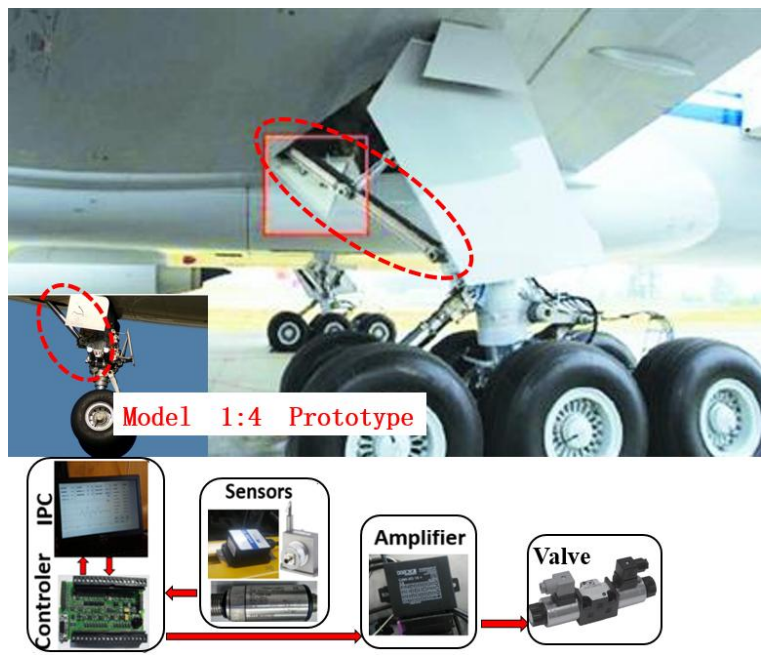

Figure.10 Model and prototype

\subsection{Analysis of experimental data}

(1)Set the appropriate outstretch step signal, so that the model cylinder's consumed time is $4 \mathrm{~S}$, prototype cylinder's consumed time is $8 \mathrm{~S}$. Model and prototype's outstretch movement are shown in Fig.11.
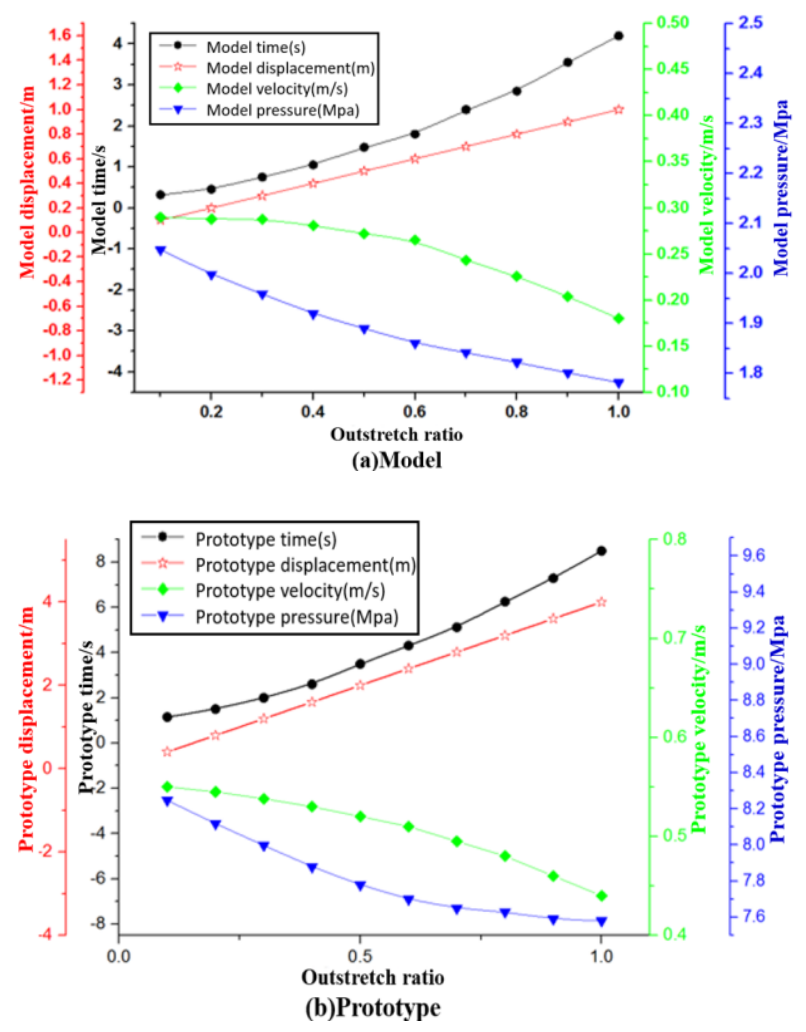


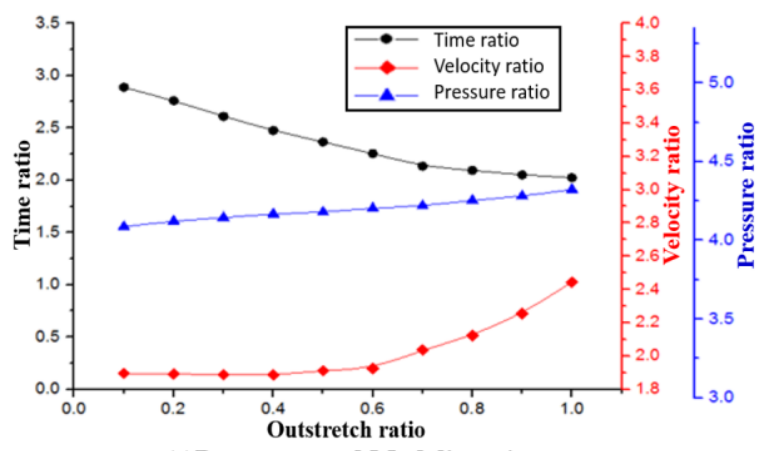

(c)Prototype and Model's ratio

Figure.11 Model and prototype's outstretch movement

Analysis: In the cylinder's outstretch stage, the accumulator discharge the oil; As the accumulator and pump provide oil together, the cylinder's speed increases firstly; When the accumulator has no oil to discharge, the pump is the only source to provide oil and the cylinder's speed decreases. Conclusion: when the model and prototype's cylinder are in the same extension ratio, the pressure ratio is about $1: 4$, the time ratio is about $1: 2$, the speed ratio is about 1: 2 , and the conclusions are consistent with the similarity ratio obtained by the matrix method and the dynamic simulation method.

\section{Conclusion}

The aircraft landing gear faces the high cost and risk problems. Through the shrunken model's experiment and the deduced similarity criterions, it can provide a reliable approach for the prototype's hydraulic system designation.

The matrix method is based on the basic factor's equal method, the relationship were built, and the similarity criterions were deduced. The dynamical model is established to imitate the electro-hydraulic proportional control process. Through the dynamical model's simulation, the similarity ratios were calculated and the deduced conclusion were consistent with the matrix method's conclusion. The length ratio is $1: 4$, the speed ratio is $1: 2$, the time ratio is $1: 2$, and the pressure ratio is $1: 4$.

The model experiment and the similarity criterions provide good references for the prototype equipment, and it can reduce the cost and risk. In the future, the similarity should be verified by more ways.

\section{Acknowledgements}

This study was funded by Qingdao Ocean Science and Technology National Laboratory Aoshan Science and Technology Innovation Project (2016ASKJ10), and thanks to Tongji University and the Institute of Fishery Machinery and Equipment.

\section{Reference}

1. Nie Hong, Wei Xiaohui. Large-scale civil aircraft landing gear key technology [J]. Journal of Nanjing University of aeronautics and astronautics, 2008, 40(4): 427-432.

2. Chen C-S, Yan D-, Tian Z-C, dynamic similarity theory analysis to the model of Yueyang Dongting lake bridge [J]. Bridge construction,2002(1):48-51.

3. Pakdee , W. , Utaivorawit, N. and Hussein, A.K. Mathematical model in the form of vorticity-stream function for porous premixed combustion , Songklanakarin Journal of Science and Technology, Vol. 37, No. 5 , 2015, pp: 595-600.

4. Al-Kayiem, H. , Hussein, A.K., Jaleel, J. and Hussain, S. Numerical Computation of 3-Dimensional Supersonic Flow Field Over Seamless Missiles , Indian Journal of Science and Technology, Vol. 7, No. 10 , 2014, pp: 1563-1572.

5. Zhang H, Lu Yaosi, Shi Lide. Similarity Analysis of Crane Model Test [J]. Hoisting and Transportation Machinery, 2000 (12): 27-29.

6. Li Zong-sen, YU Ping, HU Xiao-ping. Similarity theory's application in the design of shaking table model for concrete structure [J]. Foreign Building Materials Science and Technology, 2008, 29 (1): 55-57.

7. Wan Feng, Chen Xiaoyang, Min Yonglin, et al. Design of Simulation Experiment of Fire Gun Jet Trajectory Based on Similarity Theory [J]. Journal of Shanghai University, 2008, 14 (6): 629-632.

8. Sun Da-peng, CHENG Su-qiu, WANG Xue-song. Blasting Experiments of ship structure model based on similarity theory [J]. Blasting, 2012, 29 (2): 91-94.

9. Liu Yun, WANG Ai-lun. Study on complex system's similarity principle and similarity condition [J]. Journal of Systems Engineering, 2009,24 (3): 350-354.

10. Minxun Lu, Wanli Li. Fluid mechanics and Hydraulic Transmission [M]. Shanghai: Tongji University Press, 2006.

11. Analysis and Design of Electro-hydraulic Proportional Control System. Beijing: Mechanical Industry Press. 2005: 35-40.

12. Quan Lingxiao. Mathematical model and experimental study of bladder-type accumulator based on pipeline effect. [Yanshan University's Engineering and Master's degree thesis]. 2005

13. He Qiao-hai, Zhu Ji-li, etl. The hinged point location optimization to Telescopic boom and fork truck's luffing mechanism $[\mathrm{J}]$. The journal of China central's science and technology university, 2011, 39 :423-429. 